\title{
Study on the establishment of construction project quality evaluation system and mechanism

\author{
Li-Xin $\mathrm{Li}^{1, \mathrm{a}}$, Zhuang-Xu $\mathrm{u}^{2, \mathrm{~b},{ }^{*}}$ \\ a1850741854@qq.com, b961010988@qq.com \\ ${ }^{*}$ Corresponding author
} \\ ${ }^{1,2}$ Shenyang east road no. 9 Shenyang Jianzhu University, Liaoning province, China
}

\begin{abstract}
Keywords: Construction engineering quality, Evaluation system, Mechanism.
Abstract: In recent years, the construction project quality evaluation system is becoming more and more important. Therefore, to establish a complete and comprehensive quality evaluation system can guarantee the quality of construction projects, it can also promote the development of our country's construction project. This paper analyzes the space model of construction project quality evaluation, and has established a construction project quality evaluation ,a construction project quality evaluation and a three-dimensional quality evaluation system. It is helpful to improve the supervisory ability of the quality control and to promote the vigorous development of the construction project.
\end{abstract}

\section{Introduction}

Since the reform and opening, construction industry has developed rapidly in our country, in the position and role of the national economy has become increasingly important. With the vigorous development of the construction and the continuous expansion of construction, construction engineering quality is both the attention of the society and the focus of the construction administrative departments at all levels. This is because the construction project quality not only relates to the applicability of the project itself and construction project investment effect, and is related to the safety of lives and property of the people. Once appear quality problem, will directly affect the public interests and public safety, So construction project quality increasingly becoming the concerned focus by people. But, our country has not formed the system of construction project quality evaluation theory model and index system. The current quality evaluation system and operational mechanism imperfect, construction quality management of the competent administrative department of work and lack of reliable data source and realistic basis. This paper analyzes the conditions of our country and the government in actual needs in the work, draw lessons from foreign existing quality evaluation system to build a standardization, standardization, and feasible construction project quality evaluation system.

\section{The background and purpose of construction engineering quality evaluation system}

Along with our country economic system reform, to join the world trade organization, and the change of social environment such as globalization and impact, the construction administrative department is undergoing major reform and the shift .Under current market economic system, construction administrative departments will be on the one hand, through establishing and perfecting construction of laws and regulations system to regulate and constraint of engineering construction each responsibility main body construction quality behavior, from on macroscopic grasp and strengthen the supervision of project quality. On the other hand, through entrusting the engineering quality supervision institutions the main construction link of the construction engineering proceed spot check and supervision, effective play to the role of the society and the intermediary organizations, change the government undertakes, strengthening the management of enterprise and industry the role of self assurance and management .From the micro level, the process quality and results of construction project quality to proceed control. To this end, a new construction project quality evaluation system is to be able to reflect 
the purpose of construction engineering quality, enterprise quality and the government regulatory quality objectively the status quo, so as to the quality of the administrative manage department for construction supervision and management job to provide comprehensive about quality of engineering information. The quality management work can adapt to quality condition in the changes and development prompting the level of engineering quality further improved. In addition, abroad construction project quality evaluation practice and experience makes clear construction project quality evaluation can be for not only the government construction and management department of policy making and management measures to provide the information basis and decision-making reference, but also through the organic combination of related system and become the manage department of the powerful supplement of administrative means. In short, the new construction project quality evaluation system can comprehensively and scientifically reflect the purpose of the present situation of the construction engineering quality as well as engineering quality change trend and the reason, the quality of the administrative department for construction management work provides basis and reference, make our country's construction project in good quality control.

\section{Space model of construction project quality evaluation}

The concept of construction project quality including multiple aspects, multiple layers, can take it as a complex system, and its components are relatively not clear. Therefore, we must use system engineering method to analyze it. In order to reflect systemic and gradation characteristics, this article start from the goals and requirements of construction project quality evaluation, build the model of the " construction quality assessment space ", and try on construction project quality concept through this model for structured and systematic interpretation and description.

Construction project quality evaluation space model mainly includes three dimensions - project types, features and quality Stage of formation of quality. First of all, many types of engineering constitutes the construction of such a comprehensive integrated concept, simply by evaluating one kind of the engineering quality level to reflect the overall level of construction engineering quality, or do not consider different project types of specific conditions, general view all engineering type as the same, will be made "biased" mistakes. Secondly, each project must follow certain construction cycle, from the decision-making stage to survey and design stage and construction stage and completion and use of phase of the process, the formation of the construction project quality affected by many project construction activities, any one phase of the quality evaluation results are not as a representative of the overall level of construction engineering quality. The last, construction engineering quality connotation showed certain gradation and uncertainty. On the one hand, because of construction types are different, the importance of quality and sorting corresponding is also different, such as the general residential project, applicability and safety must be in the first place, more emphasis on the coordination of indoor environment and beautiful sex, but for the national grand theatre and other landmark for public buildings, is more emphasis on aesthetics and durability, etc. On the other hand, due to in different construction stage, the manifestation of quality is not the same, such as security during the design stage and construction stage performance is not the same.

\section{Building under the new situation of the construction project quality evaluation system}

Construction project quality evaluation system of the concept involves many aspects and many layers. Therefore, we can treat it as a constitute elements not clear enough of a complex system . This makes us on the analysis of the construction project quality evaluation system, need to use systemic method. Below we from construction project quality evaluation of target and require these two aspects, give construction project quality evaluation space model. 


\section{Set up construction project item quality evaluation}

Construction project item quality evaluation is mainly refers to all the collected in construction engineering project end based on the quantitative qualitative indicators on the current construction project construction in the process of construction quality to conduct a comprehensive assessment and demonstration to give a can objectively reflect the engineering quality of conclusion and consult, and further improve and perfect the construction quality of the project. First, the quality evaluation of construction project process. The construction quality of the engineering project in the whole project construction process is mainly reflected in the quality of investigations entities, the quality of design and construction, building materials, etc . Engineering project quality formation is the key to entity quality of the good and bad, and engineering project process quality evaluation it contains investigation of the entity, construction design entity and quality evaluation of building entity. Second, outcome quality evaluation. We can see in practice, due to the construction project is actually a kind of special craft products, the merits of the quality not only relationship construction forming process but also affects the outcome quality. Among them, outcome quality evaluation mainly include the engineering quality of merit, accident, quality complaints and project completion quality condition.

2.The establishment of quality evaluation of construction enterprises

For the quality evaluation management system of government regulation, If you want to play a role effectively, must be from local to central to build a scientific mechanism of engineering quality evaluation, in order to grasp the construction quality of the project, this helps to promptly take effective quality regulation strategies, policies and measures. From the point of practice, government regulation quality evaluation's main goal is to reflect the current situation of the engineering quality in a timely manner, and for the construction administrative department to provide effective decision making and information basis. Based on this, establish a government construction project quality evaluation management system is very important, can reflect the bottom-up engineering quality. 3.Establish construction quality assessment of government regulation

In practice you can see, construction units, supervision units and construction units and reconnaissance units in the building construction enterprise management plays a very important role, at the same time construction and design units, building supply unit and testing organizations, institutions and other companies plan approval is essential. The above mentioned eight units of organization, management and technical work, are all related to the quality of construction projects. In general, its main performance for the enterprise qualification, performance, at the same time the quality of decisions in the course of business and the implementation of other aspects of quality site, in the process of enterprise quality evaluation, it should be at different stages of the construction project for the evaluation of the foundation, at the same time to collect relevant data and information, determine the evaluation index and system, and on this basis to determine the weights of indicators, according to the specific objective demand for appropriate adjustments, and then establish mathematical model and using index method to calculate. It is concluded that the specific evaluation scores and results, this will come to be more specific enterprise evaluation findings.

\section{Conclusion}

Construction quality assessment system played a significant role in ensuring the quality of the project in this regard, our country learn advanced technology and experience of other countries, finally established a construction engineering quality evaluation system suitable to China's economic system. However, we still have to strengthen ideological value and to perfect evaluation system, to guarantee the sustainable development of our country construction enterprise. 


\section{Acknowledgements:}

This thesis is supported by the Natural Science Foundation of Liaoning Province Foundation.

Item Number: 201202178

\section{References}

[1] T.Liu and R.W.Weyers, "Modeling the dynamic corrosion process in chloride contaminated concrete structures"[J]. Cement and Concrete Research,1998,28(3):365-379

[2] Handing Guo, Yingzong Liu. The theory of construction project quality government supervision and institutional reform [J]. Construction, $2002,(1): 5-6$.

[3] Yongqiang Su. Construction engineering design quality evaluation method study [J]. Coal engineering , $2010,(7): 116-118$.

[4] Meiling Jiang. Construction project quality evaluation method research [J]. With the quality of commodity: construction and development 2011 (10).

[5] Hong-An Lu, Paul peng wang, Feng Liu etc. Construction engineering construction hazards Identification, risk evaluation and control [J]. Journal of huazhong university of science and technology, 2006, 23 (1) : 43-45. 